\title{
Cuarto a espadas: ¿Filosofía «americana»? *
}

\author{
JOSÉ GAOS
}

A lo largo del año que acaba de morir se ha debatido en estos países americanos de lengua española el tema de la creación de una filosofía peculiar de ellos. Se desea llegar a tener una filosofía mexicana o argentina, o americana, como hay una filosofia francesa, alemana o europea. Se ve al Viejo continente moribundo y se cree llamado a recoger ya y continuar su cultura a este Nuevo y flamante -en lo que pudiera haber error de precipitación, cartesiano: una sangría puede responder sanamente a un exceso peligroso de vitalidad. Se juzga a América madura ya para tal misión histórica. Es un tema que reproduce, no exactamente, pero sí en buena proporción, preocupaciones tenidas desde hace algun tiempo en España. Tambiến en España se deseó, en particular desde los primeros lustros de este siglo, iniciar definitivamente una filosofía que llegara un día a ser española en el sentido en que la francesa o la alemana, la italiana o la inglesa son tales. Se era consciente de no existir en verdad una filosofía cspañola en este sentido. Una preocupación de este objeto es patente en el centro mismo de las inspiraciones originarias y más originales de la obra de Ortega y Gasset. Lo importante de esta obra y decisivo empezó con un programa de "salvaciones» de las "circunstancias" españolas, y este programa es lo realizado en el fondo por la obra toda de Ortega desde aquella fecha, 1914, del comienzo de la primera guerra mundial, hasta la misma de hoy y de plena segunda guerra ecuménica. Las salvaciones de las circunstancias españolas no eran sino las partes y los medios de la gran salvación de la circunstancia española para y por la filosofía, porque «yo soy yo y mi circunstancia, y si no la salvo a ella no me salvo yo».

* El texto de J. Gaos (Ablaña, Asturias, 1900-México, D. F., 1969), originariamente publicado en la revista mexicana Cima (núm. 5, febrero de 1942), se halla recogido en el volumen VI (Pensamiento de lengua española) de sus Obras completas, ed. de Fernando Salmerón, Universidad Autónoma de México, 1990, pp. 291-96, con prólogo de José Luis Abellán, quien escribe en él: «Al instalarse en México, Gaos cobra conciencia del circunstancialismo orteguiano como teoría justificadora del quehacer filosófico de los pueblos hispanoamericanos, en los cuales se da como rasgo propio de sus máximas producciones intelectuales el ser emanación de sus propias circunstancias históricas, culturales, sociales, étnicas, etc. "De lo que se trata en el fondo", dice Gaos, "cs nada menos que de lo siguiente: de confinar a la Filosofía en ciertas formas pasadas o de dejarle abierta la posibilidad de ciertas formas en el futuro". Sólo si lo hacemos así habremos abierto una posibilidad a la filosofía hispánica, española o americana» (pp. 5-20, p. 19). 
La misma preocupación nos hizo a los discípulos de Ortega llegar a serlo, es decir, dedicarnos a la filosofia y trabajar por la filosofía en España y para una filosofía española, partiendo de la obra del maestro y reflexionando sobre ella. Estos antecedentes del tema debatido en estos países a lo largo del año que acaba de morir me mueven a echar mi cuarto a espadas, con la esperanza de que en este mi «tomar parte oficiosamente en la conversación de otros», que es como la Academia Española explica la frase hecha, no prepondere la «importunidad y hazañería del que se entremete en oficio o negocio que no le incumbe» sobre la «diligencia y cuidado de los oficios de amistad», que es como define sendas acepciones de la oficiosidad la misma y no siempre feliz explicadora y definidora.

No hay hasta ahora o todavía una filosofía española, o más en general, de lengua española, en el sentido en que hay una filosofía francesa o inglesa o de estas lenguas. No hay aún una filosofia americana que pueda contraponerse a la filosofía europea. Pero se desea, y vehementemente, que las haya. Es el primer punto que detiene a reflexionar. ¿Deseo justificado, acertado? ¿Es deseable tener una filosofia, hacer filosofía, poseer filósofos, ser filósofo, ante todo en general, para que pueda serlo cl tenerla de lengua española o el tenerla americana? La pregunta sorprende porque una tradición larga $\mathrm{c}$ ilustre, triunfante en definitiva a lo largo de la historia hasta nuestros mismos dias, valora la filosofía altamente, incluso como la cima de toda cultura plena y perfecta. El hecho de que esta valoración se deba primordialmente a los filósofos mismos no ha sugerido la sospecha de que pudiera ser parcial e infundada... Pero en la realidad parece ser que la filosofía no es necesaria a la vida humana individual y colectiva - no ya a una vida humana rudimentaria, sino a vidas humanas de las más altas, si es que no las supremas. Los grandes príncipes, caudillos y estadistas, los grandes héroes, los grandes santos, los grandes artistas, los mismos grandes hombres de ciencia, no son los grandes filósofos. Pueblos o culturas de los más egregios o más influyentes de toda la historia humana no han tenido, o no han tenido propiamente, en bastante volumen o con bastante originalidad, una filosofia: Egipto, Caldea, Persia, Judea, Roma, España, los pueblos eslavos... Toda una época histórica, la época positivista, ha valorado la ciencia a expensas, en contra de la filosofía, y esta valoración dista aún de haberse extinguido por completo-menos, precisamente, en América, bien que harto menos en la de lengua inglesa que en la de lengua española. Pero Atenas misma procesó, hizo huir de ella, condenó a muerte o cuando menos redujo a privada la acción y amargó la vida de los primeros y más grandes filósofos que aparecieron por ella o en ella, Anaxágoras, Protágoras, Sócrates, Platón, Aristóteles. Y parece haber razones para pensar que el recelo hacia los filósofos, la hostilidad contra ellos no era exclusiva del pueblo inculto e incomprensivo. El discurso de Calicles en cl Gorgias de Platón acaso enseña que en las clases más altas e influyentes de la ciudad existía una valoración del filosofar muy discrepante de las pretensiones tradicionales de los filósofos 
mismos. Quizá sea aquí también de tener en cuenta el hecho de que aun en las culturas y pueblos que han tenido una filosofía, ésta es, más que una función regular a lo largo de la vida de la cultura o del pueblo desde sus orígenes, un brote de florecimientos intensos, pero cfímcros, intermitentes a grandes intervalos, un tanto, pues, con caracteres de paroxismo voluptuoso y anormal. En Grecia se inicia dos o tres siglos después de Homero, que no era un fenómeno primitivo precisamente, $\mathrm{y}$ florece entre tres $\mathrm{y}$ cuatro, para no tener otro florecimiento comparable, ni de lejos, en toda la Antigüedad. Desde el cicrre de la Escuela de Atenas por Justiniano, que se toma como fecha, más símbólica que real, del fin de la filosofia antigua, pasan cinco siglos hasta el comienzo del curso ininterrumpido de la Escolástica cristiana, que dura otro tanto. Pero sobre todo la filosofia moderna culmina en los florecimientos metafísicos no habidos desde el primero y máximo florecimiento de la filosofía en Grecia: el del siglo xvir y el de fines del xvir y principios del $\mathrm{xIx}$ ambos concentrados en los pocos decenios correspondientes a la plenitud de dos o tres generaciones. Mas hay que reparar en que no se desea simplemente una filosofía, en general, sino una filosofía de lengua española o una filosofía americana, precisamente. Si se desease simplemente una filosofía, en general, ahí están o cabría esperar que estuviesen todas las filosofias de otras lenguas o todas las filosofías eurásicas antiguas, modernas y futuras -pues en lo relativo al porvenir, si no se desease precisamente una filosofía de lengua española o una filosofía americana, sino simplemente una filosofía, se podría dejar a los avezados eurásicos de otras lenguas el trabajo de seguir proveyendo de filosofía a los hispanoparlantes y a los americanos-. Pero lo que se desea es justo no seguir traduciendo o importando de ultramar, sino producir originalmente e in situ, y ocurre preguntar asimismo: esta precisión mayor del objeto deseado לes a su vez justificada, acertada? ¿Hay razón en ser hombre de lengua española o de América para no satisfacerse con la filosofía, por ejemplo, de lengua inglesa o con la filosofía europea, si no asiática? No ya los cualesquiera, sino los filósofos mismos de lengua latina de la Antigüedad y de la Edad Media juzgaron deber profesar la filosofia griega. Los cartesianos o los positivistas, o los kantianos, hegelianos o krausistas de otros países que Francia y Alemania y hasta de otros continentes que el europeo juzgaron o juzgan aún deber profesar filosofías de lenguas y países extranjeros. Los neoescolásticos que hay por todo el mundo juzgan deber profesar la filosofía de la Europa occidental medieval. Y, en fin, no es nada seguro que Descartes o Comte, Kant o Hegel quisieran hacer una filosofía francesa o alemana, ni ninguna menos que una filosofía universal e incluso eterna, por no decir Platón o Aristóteles, cuyas intenciones, más o menos conscientes, no podían ser exactamente las mismas, por la scncilla razón de que ecumene e historia eran para ellos harto más reducidas. El deseo, el afán deliberado, expreso, de hacer y llegar a tener una filosofía original, peculiar, de la propia lengua o del propio territorio, más o menos extensamente tomado, parece, pues, novedad no jus- 
tificada del todo por la historia, al menos. En principio es posible que lo deseable en o para unos pueblos o culturas no lo sea en o para otros. Lo primero que habría que considerar a fondo en este tema de la filosofía de lengua española o de la filosofía americana sería, en suma, si tener una filosofia, hacer filosofía, poseer filosofía, ser filósofo, es realmente algo tan deseable como parece o se cree, así en general como particularmente en o para los países de lengua española o de América.

Mas admitamos que ello sea tan deseable como parece o se cree en o para todos los pueblos o culturas. La cuestión pasaría a ser ésta: ícómo dar al deseo satisfacción? Una filosofía, ya en general, no se diga caracterizada como original, como peculiar de una lengua o de una parte de la Tierra, ¿no es exclusivamente un espontáneo fruto?, iserá posible intencionalmente lograrla? Es bien sabido que los que partieron para la guerra de los Treinta Años no particron para ella. ¿Es que Tales de Mileto habrá partido para la filosofía universal o siquiera para la griega, o al menos Descartes para la francesa, ya que no para la moderna? Imaginemos que absolutamente todos los coparlantes de la lengua española o todos los americanos compartiesen el interés por la creación de una filosofía de nuestra lengua o de este continente, y que todos estos millones de scres humanos nos pusiéramos a pensar, anhelar y decir enardecidamente: iay, no tenemos una filosofía!, iqueremos tener una filosofía!, thay que crear la filosofía de lengua española!, icreemos la filosofía americana! - un volumen de voluntad que se alzase tan extenso, tupido, soberbio y rumoroso como las selvas de este Nuevo Mundo hasta los cielos de los dioses propicios: isería poderoso para crear la filosofía de lengua española o la filosofía americana, si la filosofia fuese resultado de dotes otorgadas a unos y negadas a otros de los grupos humanos parlantes de las distintas lenguas - habitantes de las distintas partes del globo terráqueo y los americanos o los hispano-parlantes formásemos entre los segundos? Pero sería un deseo erróneamente ilustrado aquel al que consideraciones semejantes detuviesen en el camino de perseguir su satisfacción. La idea de la imposibilidad de radicales innovaciones en el futuro es una idea filosófica de la historia nada segura precisamente. Dado el deseo de llegar a tener una filosofía original, lo único congruente con él es esforzarse por hacer filosofía, por filosofar- no dejar de hacer nada de lo que esté en el propio poder por conseguir el fin deseado, decidida, denodadamente arriesgarse a perder a la postre el tiempo... Porque: acaso una filosofía no pueda ser la satisfacción de un deseo de ella sino en cuanto este deseo sea ya un deseo filosófico, un deseo inserto en un filosofar; deseo de filosofía quizá no pueda ser sino deseo de perseverar en un filosofar en el que uno se encuentra ya; es posible que no lo sea ponerse deliberadamente a filosofar, sino que sólo quepa encontrarse puesto ya a ello, filosofando, siendo filósofo. En este caso, la cuestión sería: el deseo de una filosofía de lengua española o una filosofía americana des ya filosófico?, ¿está inserto ya en un filosofar? Los hombres de lengua española o de América ise encuentran ya 
filosofando?, estas preguntas mismas ison filosóficas?... En todo caso, aquello a que habría que ponerse o a que habría que encontrarse puesto, sería la filosofía, pura y simplemente. Ya quedó insinuado: la filosofía griega o la francesa o la alemana no son tales porque los filósofos griegos, franceses o alemanes se hubiesen propuesto que tales fuesen, ni menos la filosofía europea porque se lo hubiesen propuesto los filósofos europeos, sino porque unos griegos, franceses, alemanes o europeos en general hicieron filosofía. La filosofía resulta de la nacionalidad o la «continentalidad», sit venia verbo, de sus autores, quizá incluso a pesar de ellos, sin más que ser filosofía, pero auténtica. Si españoles, mexicanos o argentinos hacen suficiente filosofía, sin más habrá filosofía española, mexicana, argentina, americana. ¿Perogrullada? Quizá necesaria... La filosofía ¿sería original de suyo, por su naturaleza? ¿Filosofía (si auténtica) $=$ original?... La cuestión no está, pues, en hacer filosofía española $o$ americana, sino en hacer españoles o americanos filosofía. De lo que hay que preocuparse no es, en fin, de lo español o lo americano, sino de lo filosófico de la filosofía española o americana. ¿Cómo se hace filosofía? Parece que más exactamente: ¿cómo hacer filosofía? Ésta es la cuestión. Ahora bien, entre «hacer filosofia» 0 «filosofar» $y$ «filosofia» no hay diferencia. Por ello tampoco viene a haberla ente «icómo hacer filosofía?» o «bcómo se hace filosofía?» y «iqué es filosofía?». La cuestión de que se trata puede por ende formularse también con esta última pregunta. Pero así formulada o simplemente reducida a las anteriores se revela menos perogrullesca y desde luego excesiva ya para este artículo. Quizá la lectura de él haya hecho al interesado que lo hubiera menester percatarse de la cuestión de que realmente se trata con el tema de la creación de una filosofía peculiar de estos países, y si el interesado posee una solución a esta cuestión, si tiene una idea de la filosofía, sabrá eo ipso lo que habría que hacer $\longrightarrow$ o seguir haciendo-. Por mi parte espero merecer oportunidad de tornar al punto en que pongo este final. 